\title{
On a so-called demonstration of the causal power of absences
}

Article

Accepted Version

Oderberg, D. (2019) On a so-called demonstration of the causal power of absences. Studia Neoaristotelica, 16 (1). pp. 141-148. ISSN 1804-6843 doi: https://doi.org/10.5840/studneoar20191614 Available at https://centaur.reading.ac.uk/84646/

It is advisable to refer to the publisher's version if you intend to cite from the work. See Guidance on citing.

To link to this article DOI: http://dx.doi.org/10.5840/studneoar20191614

All outputs in CentAUR are protected by Intellectual Property Rights law, including copyright law. Copyright and IPR is retained by the creators or other copyright holders. Terms and conditions for use of this material are defined in the End User Agreement.

\section{www.reading.ac.uk/centaur}

\section{CentAUR}

Central Archive at the University of Reading

Reading's research outputs online 


\section{WARNING}

AUTHOR'S DRAFT

Tyron Goldschmidt has recently published a non-paper in which he claims to demonstrate the causal power of absences. His non-pape s, $\mathrm{p}$, $\mathrm{c} / \mathrm{a}$ empt, age The non-paper is ingenious and at first 'glance' the 'reader' might think that the absence of words on the page does pr 4 at hega ve eings indit ally a ses ates achas urp se $\Delta$ isap oin h it. but also lacks causal power. Serious metaphysical problems pile up if we suppose otherwise.

Key words: absence causation, powers, negative truths, negative being

Tyron Goldschmidt has recently not written what is, to my mind, the best non-paper I have not read in decades. ${ }^{1}$ In it he purports to demonstrate, albeit without saying so in the paper, that absences have causal power, something many reality-minded metaphysicians vigorously deny. ${ }^{2}$ His non-paper, in other words, consists of no words whatsoever - a mere empty page. True, he does have metaphysicians on his side ${ }^{3}$ but in this case the absence of a

\footnotetext{
1 'A Demonstration of the Causal Power of Absences', Dialectica 70 (2016): 85.

${ }^{2}$ See, for example, George Molnar, 'Truthmakers for Negative Truths', Australasian Journal of Philosophy 78 (2000): 72-86; David Lewis, 'Causation as Influence', in J. Collins, N. Hall, and L. Paul (eds.), Causation and Counterfactuals (Cambridge, MA: MIT Press/Bradford Books, 2004), 75-106; Helen Beebee, 'Causing and Nothingness', in Causation and Counterfactuals, 291-308.

${ }^{3}$ See, for example, Stephen Barker and Mark Jago, 'Being Positive about Negative Facts', Philosophy and Phenomenological Research 85 (2012): 117-38; D. H. Mellor, The Facts of Causation (London: Routledge: 1995).
} 
good many of them indicates no lack of a sound ontological sense - not so much a taste for desert landscapes, à la Quine, but more a preference for oases over mirages.

To grasp the full force of my response to Goldschmidt, however, each reader must not read his ingenious contribution for himself. Each reader must, in the spirit of Hume, turn

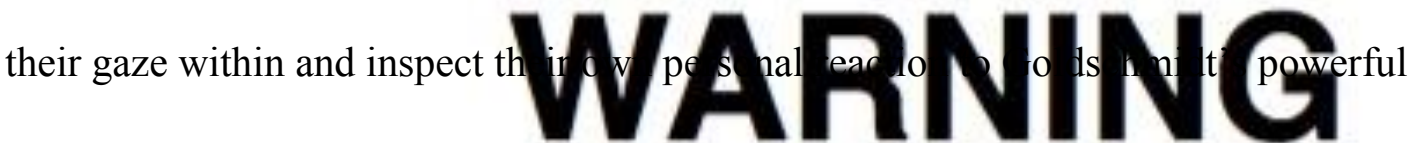
challenge. I do not want to bias the reader with a report of the result of my own inward turn.
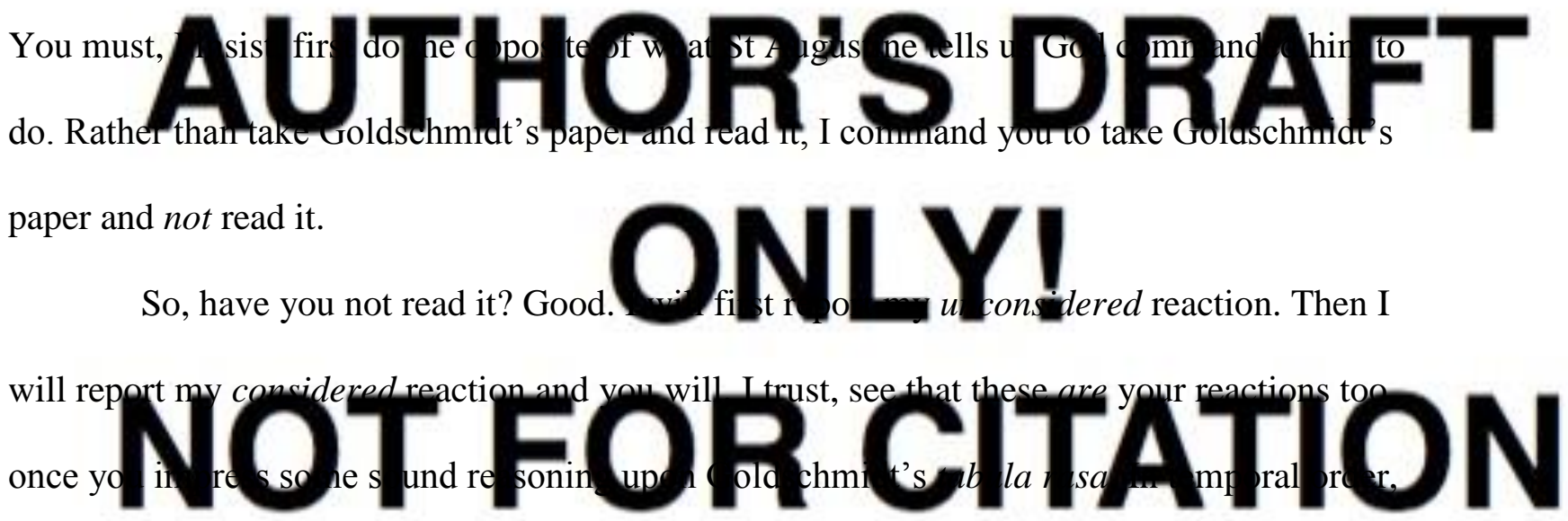

I initially reacted thus. (1) How annoying, I've only downloaded the cover sheet of the paper. I must download it again. (2) How incredibly annoying, I've still only downloaded the cover sheet! (3) No, I haven't done anything wrong; my computer is not playing up; my internet connection is fine. So the publisher has made a mistake and not posted Goldschmidt's entire paper. (4) But at the top of the page the paper is reported as being only one page long! (5) Oh, I get it. But wait! Goldschmidt has done it! By Heaven, the lack of text has really - really - surprised me. I've been metaphysically smacked in the face by, of all things, an absence!

Needless to say, Goldschmidt achieved, at least with me, his intended effect in a way that no philosophy paper I have ever not read has ever done - at least so quickly. A psychological effect does not, however, a piece of philosophical reasoning make. We philosophers are not lacking in vulnerability to intellectual sleights of hand. Fortunately, having been thinking about this topic for quite a while, and not allowing myself to mistake 
(1)-(5) above as containing any kind of rational persuasion, I feel on solid ground in objecting that Goldschmidt has not in the least made out his case for absence causation.

Why not? Well, it is hard to deny that I was struck by something. I was really caused to be surprised. So what surpri

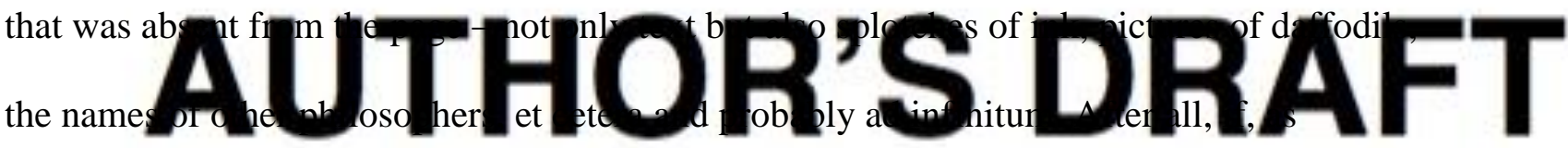

Goldschmidt believes, absences have causal power, then they must be both real and capable of individuation, so he cannot deny that 1 th e th a sences exist those, to be precise, that are absences from his non-paper. So I should have been surprised by all these other absence a Not at all, comes the reply: for you were not expecting there to be pictures of daffodils or splotches of ink. True, but what was I expecting? Suppose Goldschmidt's nonpaper had contained only the text of the first page of War and Peace. Then it would still have been a non-paper, only in a different way. I would still have been surprised, but for a different reason. In the first case I expected some text; there wasn't any; and I was surprised. In the second case I also expected text, and I got it; no surprise there. But I also expected philosophical text, not a page of Tolstoy; and so I was surprised by that. By what - by the lack of philosophical text? Well, Goldschmidt's actual non-paper also lacks philosophical text, and the absence of text is not identical to the absence of philosophical text. So why was I not surprised by the lack of philosophical text in his actual non-paper? Why no causal 'oomph' (or 'biff') both from the lack of text and from the distinct lack of philosophical text? Will Goldschmidt say that I did not expect philosophical text, only text? How wrong he

\footnotetext{
${ }^{4}$ David Lewis (using Peter Menzies's term), 'Void and Object', in Causation and Counterfactuals, 277-90.
} 
would be, for I can only avow that I did expect both from his actual non-paper. So why didn't they both surprise me? Again, I can only report that what surprised me was the lack of any text. To be sure, had there been a page of Tolstoy I then would have been surprised by the lack of philosophical text, but generated would have been different.

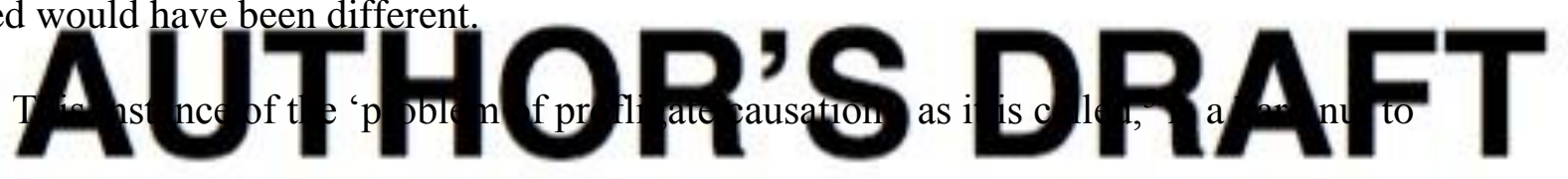

crack. Goldschmidt might insist that the absence of text from his non-paper, and the absence of philosophical text, are one and the sar e ab in th wor the can have one without the other in some possible world, but in the actual world, as far as his actual non-

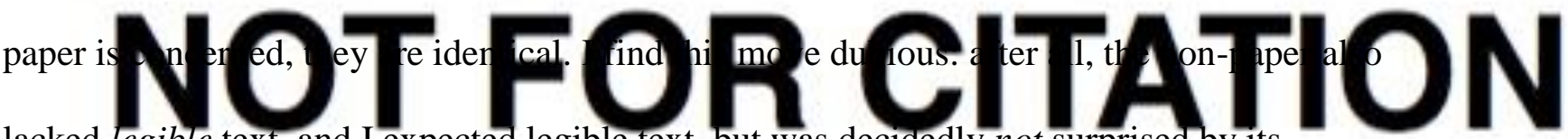
lacked legible text, and I expected legible text, but was decidedly not surprised by its

absence. So what is the single, causally operative absence Goldschmidt could have in mind if he made such a move - the lack of black, legible, justified, first-line indented, evenly spaced prose? (Just go through that journal's style guidelines: to be frank, I expected a decent amount of these to characterise the text I expected.) I'm having trouble identifying the absence itself, let alone knowing whether it literally struck my mind, thereby generating surprise.

Yet suppose we have pinned down the absence. Since not all of its components struck me (such as the lack of legibility - although I expected it, I tell you!) - in fact only one component did, namely the lack of text - in virtue of what is it the case that this component did surprise me and the others did not? What move could Goldschmidt make now? Perhaps rank the expectations in order of strength? He might say that I was only surprised by whatever I expected most of all, which was just text. This looks gratuitous. Assuming we

\footnotetext{
${ }^{5}$ Peter Menzies, 'Difference-Making in Context', in Causation and Counterfactuals, 139-80.
} 
could even rank the levels of strength of my relevant expectations (what a task...), why shouldn't I have been struck by the lack of the two features I expected the most, say both text and philosophical text, or the top three (add say principle cou

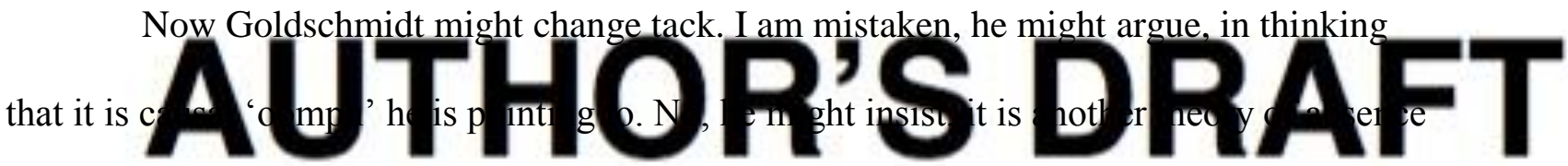
causation he is defending, such as a Lewisian counterfactual theory (with, let us not forget,

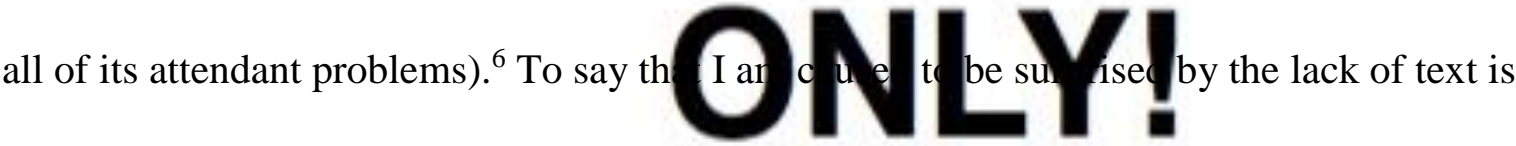
not to say that there is a causal relation at work, only that if there had been text I would not

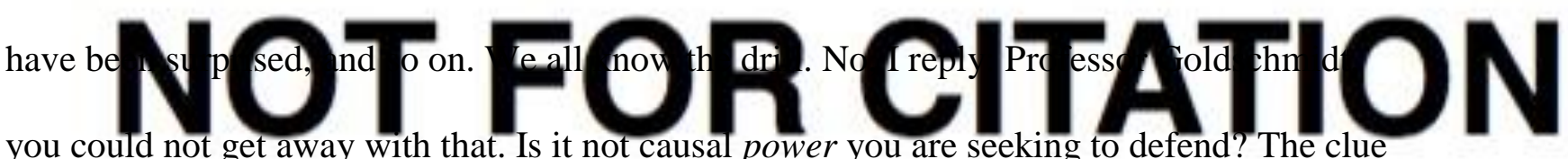
is in the title of your non-paper! You think absences can be causally operative ${ }^{7}$ not merely causally relevant ${ }^{8}$ or causally explanatory. ${ }^{9}$ We can all agree that absences, whatever they are, have a causally relevant, explanatory role: you did not have to go to the inordinate effort of not writing your non-paper to convince anyone of that.

The metaphysical problems are piling up. To add a cherry to the cake, consider now my reaction rather than the alleged absence I reacted to. I was, I admit, quite surprised. I expected there to be text. But note: I also wanted there to be text, yet I did not feel that my desire had been frustrated. I hoped for text, but I did not feel my hopes had been dashed. I looked forward to text, but its absence did not make me feel deprived of an intellectually enjoyable hour or two reading Professor Goldschmidt's limpid prose. Heavens above - I deserved text! But did I feel cheated by its absence? Not at all! On the contrary, once I got

\footnotetext{
${ }^{6}$ Lewis, 'Causation as Influence'; 'Void and Object'.

${ }^{7}$ Contra Molnar, 'Truthmakers for Negative Truths'.

${ }^{8}$ As per Boris Kusko, 'The Reality of Absences', Australasian Journal of Philosophy 84 (2006): 21-37.

${ }^{9}$ As per Beebee, 'Causing and Nothingness'.
} 
the joke I gave the silent, knowing guffaw that only a smug academic could produce. Oh, by the way: I was not expecting, nor did I particularly want, to have an intellectual joke played on me, but I laughed all the same.

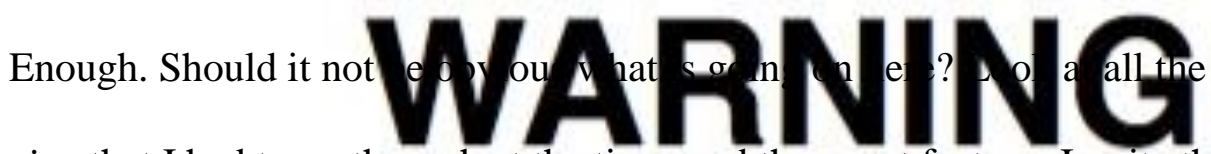

ratiocination that I had to go through at the time, and then post facto as I write this real paper

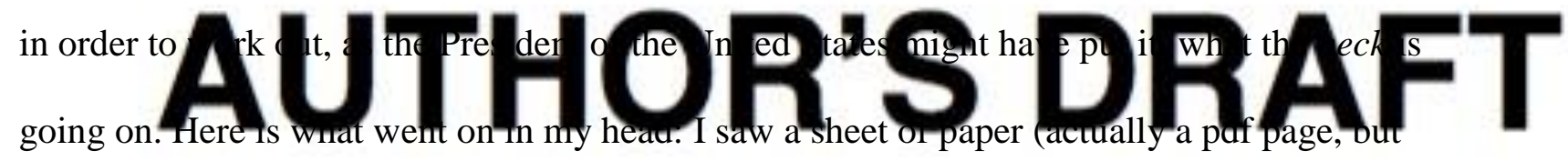

let's talk the old-fashioned way) with a tit
impinged on my sense organs, causing a

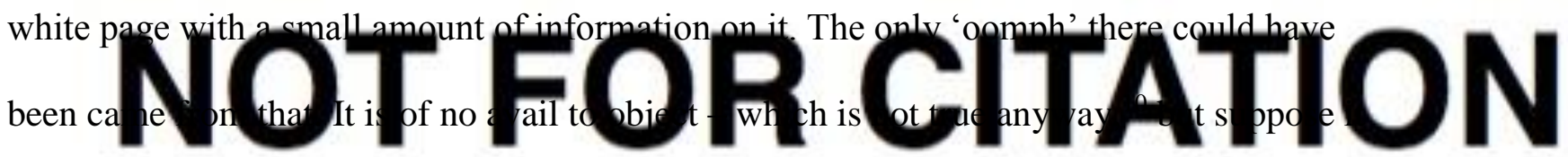

were - that all seeing is seeing as or seeing that, that one could question whether I even saw

a page, or saw any text at all as opposed to a patch of white and some smaller black shapes

overlapping the white. The question is whether the absence of relevant text - the expected

philosophical text - could have any 'oomph' of its own, whether or not the other things I am

certain I saw also have 'oomph'. As long as something has 'oomph', even if it be just pixels

or ink marks, we have the required contrast with absences.

Once the page and the small amount of text on it had caused my sensory experience,

I was surprised - not by something else I saw, but once I had realised that there was nothing else on the page, that the page lacked what I expected to see as well. My question to myself was along the lines of, 'What am I looking at here? The page is blank save for an author and title!' I knew already what I was seeing, but I hadn't yet worked out why I was startled. 'Oh, I see', my internal monologue continued - 'I am surprised because there is no other text'. My

\footnotetext{
${ }^{10}$ There is a world of difference between the question whether one perceives text and whether one perceives an absence of text, and also between whether one perceives ink marks as text and whether one perceives that a page lacks text at all.
} 
'I see' was not a realisation that I was seeing an additional being, to wit an absence of text.

Were I to have seen that, I would have seen it at the same time as I saw the page, author and title, with no delay for confusion and head scratching. After all, if the absence were real and had 'oomph', there is no reason why its 'oomph' should have been any less powerful, any slower acting, than the 'oomph of sed th the the But I did delay. I pondered. I thought I had made a mistake. Then I thought the publisher had

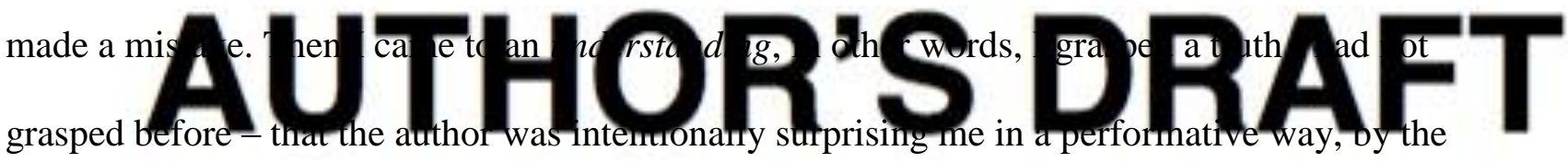
very 'paper' itself, and this in virtue of th
was supposed to lack it.

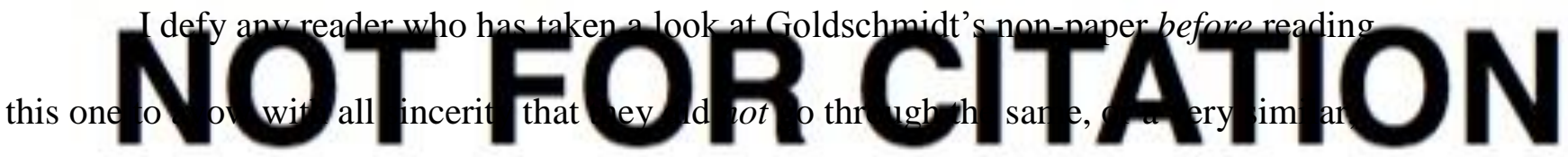
ratiocinative process before realising what was going on. Now we often ratiocinate, of course, about what it is we are perceiving. We have to interpret the world around us, whether consciously or via unconscious, hard-wired mechanisms. Of itself the need for ratiocination proves nothing. I ask the reader, though, to attend to the particular train of thought that accompanied their inspection of Goldschmidt's purported demonstration. Did you just see an absence? No, I insist - you did not. You never took yourself to be doing such a thing. You saw a page and you saw a bit of text, but you had to work out what that meant as far as absences themselves are concerned. After all, the title of the paper, which you did see, directed you to just such reflection. Ask yourself: if you saw an absence, why did it take you so long to realise that you saw it? Did you have to train yourself to see it? How did that work, and why was it even necessary? Or did you, as I contend, come to the realisation, after some ratiocination, that there was no text where it should have been? 
The metaphysical moral we should draw from all this is that we have here no demonstration of the causal power of absences. We can account for what we need to account for in other, metaphysically palatable ways. We do not need to reduce putative absence come into play, but we can also on the sort far $\mathrm{m}$ res the recognise the existence of potentialities, states of need normative realities, privations, and the full machinery of a neo-Aristotelian feor o bo gith th machinery put to work, we can find positive truthmakers for negative truths without having to postulate real absences

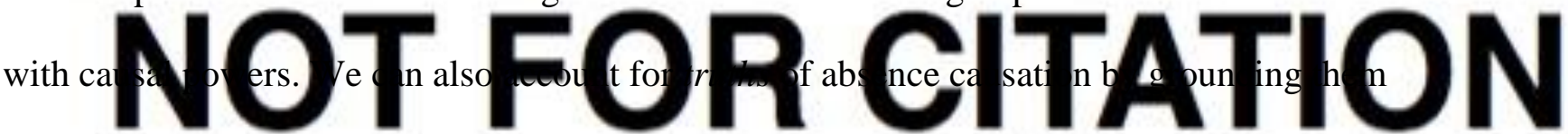
in real causal processes, in actualities with causal powers and attendant potencies. Absences are not real beings, on this theory, but they are 'beings of reason' as the Scholastics put it what we grasp insofar as we grasp truths in which absences play an ineliminable role. ${ }^{11}$

Why all the presumptuous psychologising, you may ask? Well, isn't Goldschmidt's non-paper just one big exercise in psychology? Isn't he asking us to turn the gaze within and see what he claims he sees? So I turn my gaze within and I do not see nothing as he would have it; but I do see nothing of the sort.

${ }^{11}$ For the theory undergirding all of this, see my forthcoming book, The Metaphysics of Good and Evil. 